\title{
Left atrial scar burden determined by delayed enhancement cardiac magnetic resonance at post radiofrequency ablation: association with atrial fibrillation recurrence
}

Gerd Brunner ${ }^{1,2^{*}}$, Lucien Abboud ${ }^{2}$, Kamran A Shaikh², Amish S Dave ${ }^{2}$, Joel Morrisett ${ }^{1}$, William A Zoghbi ${ }^{2}$, Miguel Valderrábano², Dipan J Shah²

From 15th Annual SCMR Scientific Sessions

Orlando, FL, USA. 2-5 February 2012

\section{Background}

Left atrial (LA) radiofrequency (RF) ablation has become routine treatment for atrial fibrillation (AF) but still suffers from AF recurrence requiring a repeat procedure. LA-RF ablation success rates vary between $53 \%$ and 85\%. Delayed-enhancement Cardiac Magnetic Resonance (DE-CMR) can be used to noninvasively visualize LA hyperenhancement (scar). We have utilized DECMR to quantify LA scar extent post LA-RF-ablation and related this measure to AF recurrence.

\section{Methods}

Twenty-seven patients (62.0 \pm 11.1 years, 20 males) with paroxysmal and chronic AF underwent LA-RF-ablation and subsequent DE-CMR, an average of $260.7 \pm 314.7$ days post procedure. The DE-CMR procedure was performed utilizing a navigated 3D inversion recovery gra- dient echo sequence (Siemens 1.5T Avanto or 3.0T Verio) approximately 15 minutes after administration of $0.2 \mathrm{mmol} / \mathrm{kg}$ Diethylenetriaminepentaacetic Acid-Gadolinium (DTPA-Gd, Magnevist, Berlex Laboratories, Wayne, NJ). All scans were electrocardiographically (ECG)-gated and acquired during a $150 \mathrm{~ms}$ window in mid-diastole with navigator-gating and fat suppression. We have developed an image analysis method and graphical user interface to semi-automatically quantify hyperenhanced regions in the LA wall (scar). LA scar was quantified by a single experienced observer blinded to patient data. LA-scar measurements were normalized by LA size. The intra-class correlation coefficient (ICC) was used to assess intra-observer variability of 4 randomly selected scans which were re-read one week later. Variables were tested for normality with the ShapiroWilk test and a p-value $<0.05$ was considered statistically

Table 1 LA-scar quantification in AF patients.

\begin{tabular}{cccc}
\hline Variable & AF-Recurrence $[\mathbf{N}=\mathbf{1 3}$, mean, std] & AF-Free [N=14, mean, std] & P-value \\
\hline LA-Volume [mL] & $128.49 \pm 44.0$ & $96.0 \pm 38.5$ & 0.06 \\
LVEF [\%] & $58.93 \pm 12.1$ & $64.85 \pm 6.2 .1$ & 0.092 \\
LA-scar [cm $\left.{ }^{2}\right]$ & $11.40 \pm 7.6$ & $16.56 \pm 5.25$ & $\mathbf{0 . 0 3 6}$ \\
Age [years] & $61.67 \pm 9.3$ & $62.23 \pm 12.8$ & 0.891 \\
Gender [no. males] & 10 & 10 & - \\
\hline
\end{tabular}

LA= left atrium; LA scar (hyperenhanced area) was normalized by LA volume. $N=$ number of patients; Std=standard deviation; RF= radio frequency; LVEF: left ventricle ejection fraction; AF: atrial fibrillation. 


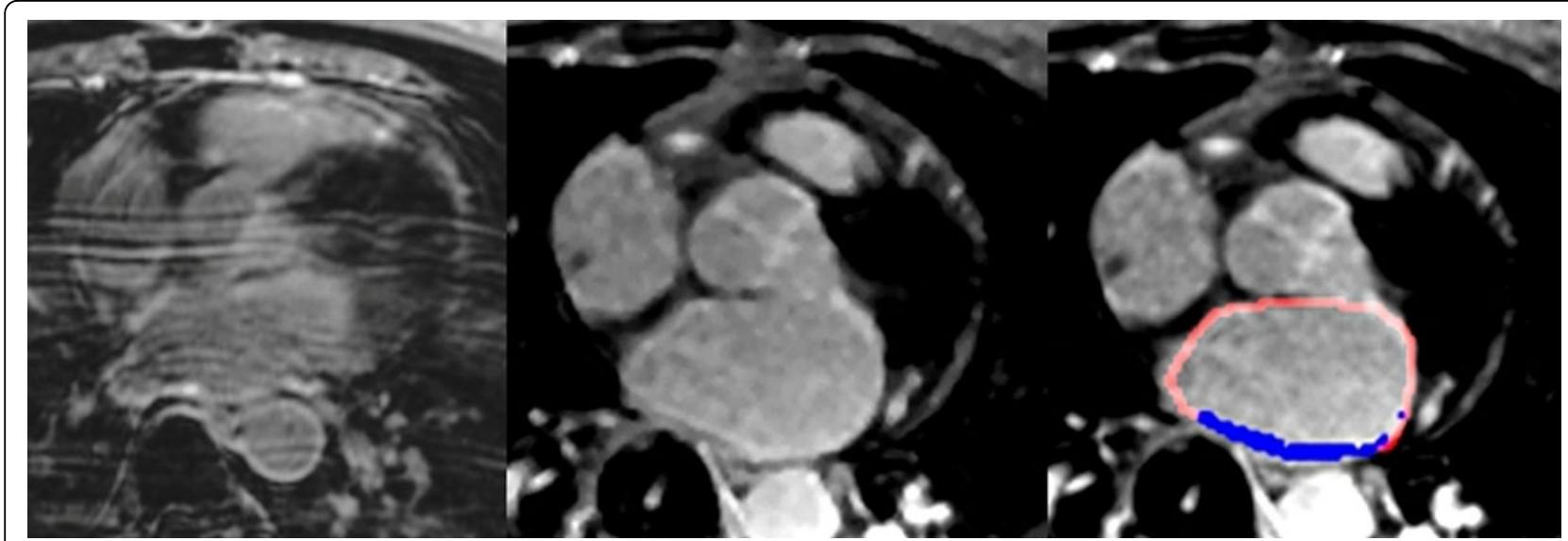

Figure $1 \mathrm{DE}-\mathrm{CMR}$ images of the left atrium (LA) obtained with a Siemens 1.5T Avanto (left and middle panels). The right panel shows the result of the semi-automated LA scar segmentation for the center panel. The left atrium is indicated by the red contour and the blue area highlights hyperenhanced regions (scar).

significant (all tests were 2-sided). All patients provided informed consent.

\section{Results}

The DE-CMR scans were performed $260.7 \pm 314.7$ days after the initial LA-RF- ablation procedure (Figure). AF recurrence was noted to occur in 13 (48\%) patients whereas 14 (52\%) patients demonstrated no AF recurrence. There was a trend toward a larger LA-volume in the AF-recurrence group $(128.49 \pm 44.0 \mathrm{ml}$ vs. $96.0 \pm 38.5$ $\mathrm{ml} ; \mathrm{p}=0.06$, see Table 1 ). Left ventricle ejection fractions (LVEF) were smaller in the AF-recurrence group but the difference was not statistically significant $(58.93 \pm 12.1 \%$ vs. $64.85 \pm 6.2 .1 \%, \mathrm{p}=0.092$ ). Average analysis time per scan was $14.5 \pm 7 \mathrm{~min}$ and intra-observer variability was excellent (ICC $=0.99)$. LA-scar was normally distributed $(\mathrm{p}=0.151)$. Average LA scar extent, quantified in post LA-RF-ablation DE-CMR scans, was significantly larger in recurrence-free AF patients $(16.56 \pm 5.3 \mathrm{~cm} 2)$ when compared with individuals with AF-recurrence (11.40 $\pm 7.6 \mathrm{~cm} 2 ; \mathrm{p}=0.036$ ). The results indicate that there is a significant inverse relationship between LA-scar burden and AF-recurrence.

\section{Conclusions}

LA scar extent can be reproducibly quantified with DECMR; and a lower scar burden post LA-RF-ablation is associated with AF recurrence.

\section{Funding}

This work was supported in part by NIH grant T32HL07812.

\section{Author details}

${ }^{1}$ Section of Atherosclerosis and Vascular Medicine, Department of Medicine, Baylor College of Medicine, Houston, TX, USA. ${ }^{2}$ The Methodist DeBakey Heart \& Vascular Center, Houston, TX, USA.

Published: 1 February 2012

\section{doi:10.1186/1532-429X-14-S1-P204}

Cite this article as: Brunner et al:: Left atrial scar burden determined by delayed enhancement cardiac magnetic resonance at post radiofrequency ablation: association with atrial fibrillation recurrence. Journal of Cardiovascular Magnetic Resonance 2012 14(Suppl 1):P204.

\section{Submit your next manuscript to BioMed Central and take full advantage of:}

- Convenient online submission

- Thorough peer review

- No space constraints or color figure charges

- Immediate publication on acceptance

- Inclusion in PubMed, CAS, Scopus and Google Scholar

- Research which is freely available for redistribution
Biomed Central 